\title{
In vitro preventive effects of nitrate tolerance by a polyphenol-enriched extract of Hibiscus sabdariffa
}

\author{
Mamadou Sarr ${ }^{1,2 \star}$, Fatou B. Sar ${ }^{3}$, Maboury Diao $^{4}$, Saliou Ngom ${ }^{5}$, Alassane Wele ${ }^{6}$, Lamine \\ Guèye $^{7}$, Fallou Cissé ${ }^{8}$ and Annelise Lobstein ${ }^{9}$ \\ ${ }^{1}$ Unité Mixte Internationale de Recherches (UMI 3189) 'Environnement, Santé, \\ Sociétés' CNRS-UCAD-CNRST-UNIV, Bamako, Mali. \\ ${ }^{2}$ Laboratoire de Physiologie Pharmaceutique, FMPOS, UCAD, Dakar, Senegal. \\ ${ }^{3}$ Laboratoire de Physiologie et Explorations fonctionnelles, FMPOS, UCAD, Dakar, Senegal. \\ ${ }^{4}$ Service de Cardiologie, Hôpital Aristide LeDantec, UCAD, Dakar, Senegal. \\ ${ }^{5}$ Laboratoire d'innovation thérapeutique, UMR 7200, Faculté de Pharmacie, Illkirch, Université de Strasbourg, France. \\ ${ }^{6}$ Laboratoire de Chimie Thérapeutique, FMPO, UCAD, Dakar, Senegal. \\ ${ }^{7}$ Unité Mixte Internationale de Recherches (UMI 3189) 'Environnement, Santé, \\ Sociétés' CNRS-UCAD-CNRST-UNIV, Bamako, Mali. \\ ${ }^{8}$ Laboratoire de Physiologie et Explorations fonctionnelles, FMPOS, UCAD, Dakar, Senegal. \\ ${ }^{9}$ Laboratoire d'innovation thérapeutique, UMR 7200, Faculté de Pharmacie, Illkirch, Université de Strasbourg, France.
}

Accepted 8 February, 2013

Treatment failure or tolerance, which rapidly leads to a reduced hemodynamic effects and therapeutic efficacy is the major limitation of long-term use of nitrates, including nitroglycerin (NTG) in the treatment of coronary artery disease. These effects are most often associated with oxidative stress. Thus, in this work, we were interested in the prevention of nitrate tolerance by the antioxidant compounds from Hibiscus sabdariffa L. crude extract, a plant from the Senegalese Pharmacopoeia, rich in polyphenols. Thoracic aorta segments without endothelium were taken from rats and incubated in isolated organ chambers. The vessels were then pre-exposed with the $H$. sabdariffa polyphenolic extract (HSE, $5.10^{-2} \mathrm{~g} / \mathrm{l}$ ) or antioxidants such as $\mathrm{N}$-acetyl cysteine (NAC, $10^{-3} \mathrm{M}$ ) or vitamin C (VIT C, $10^{-2}$ $M)$, taken as reference. After a 30 min treatment, aortic segments were exposed to NTG $(50 \mu \mathrm{M}, 1 \mathrm{~h})$ to induce tolerance state before being contracted to adrenaline $\left(10^{-8}\right.$ to $\left.10^{-5} \mathrm{M}\right)$, and then relaxed with NTG $\left(10^{-9}\right.$ to $\left.10^{-5} \mathrm{M}\right)$. Polyphenols from $H$. sabdariffa potentiated the relaxant response to NTG, whatever the state of vascular tolerance; the HSE partially corrected the in vitro nitrate tolerance. This work suggests interesting therapeutic perspectives by improving the response to treatment with nitrates in coronary patients.

Key words: Nitrate tolerance, antioxidant, vascular diseases, therapeutic agents, medicinal plants.

\section{INTRODUCTION}

Angina pectoris, usually due to coronary heart disease, is recognized as a transient retrosternal pain syndrome and

${ }^{*}$ Corresponding author. E-mail: mamadou2.sarr@ucad.edu.sn. Tel: +221 8652341 (Poste 279). Fax: +221 8252952. characteristic of myocardial ischemia. It occurs more readily after 50 years and more frequently favored by risk factors: hypertension, diabetes, dyslipidemia, smoking, obesity, heredity (Stritzke et al., 2009). Prevalence is difficult to quantify and varies by country. However, it is higher in industrialized countries where it affects about $2 \%$ of the population (Carevic et al., 2007). In the 
treatment of myocardial infarction, the first-line drugs consist of nitrates, including nitroglycerin. However, their long-term use is limited by a therapeutic escape or tolerance effect, which decreases the therapeutic efficacy of the drug, compromising the patient's prognosis (Munzel et al., 2005; Daiber et al., 2010a; b; Munzel, 2008).

In the mechanisms of tolerance to nitrates, two major phenomena are discussed:

(i) a pseudotolerance phenomenon (Munzel et al., 2005), linked to a neurohormonal activity, associated with volume expansion, both intended to limit the fall in blood pressure associated with a vasodilatory nitrates effect, and; (ii) a direct loss of vascular response called vascular tolerance (Wenzl et al., 2009; Fink and Bassenge, 2002; Wang et al., 2002b), whose mechanism is not fully elucidated. In the current state of knowledge, oxidative stress is a major cause of this phenomenon (Fadel et al., 2012; Oelze et al., 2010; Daiber et al., 2004; 2005; Mollnau et al., 2006).

Thus, our hypothesis derives from the antioxidant capacity of compounds to reduce or prevent vascular tolerance to nitrates, by reducing oxidative stress.

Antioxidant compounds have shown a growing interest to researchers. Indeed, studies have demonstrated their ability to prevent nitrate tolerance in animal models, including humans. These agents include natural antioxidants such as vitamin C, vitamin E and plant polyphenols. However, studies have shown that vitamins are able to produce free radicals with cytotoxic effects (Satoh et al., 1996; Kagan et al., 1994; Cai and Harrison, 2000), unlike the polyphenols. They are abundantly synthesized by plants, hence our interest in $\mathrm{H}$. sabdariffa $L$., a plant from the Senegalese Pharmacopoeia, rich in polyphenols. Therefore, the objective of this work was to study the experimental conditions for the prevention of tolerance to nitroglycerin, and specifically demonstrate the in vitro antioxydant and preventive effects of $H$. sabdariffa.

\section{MATERIALS AND METHODS}

\section{Drugs}

Norepinephrine and Acetylcholine were purchased from Sigma Chemical Co; N-acetyl cysteine (Fluimucil ${ }^{\circledR} 5 \mathrm{~g} / 25 \mathrm{ml}$, solution for infusion) and Vitamine C (VITAMIN C 10 Percent, AGUETTANT ${ }^{\circledR}$, solution for injection, for infusion) was purchased from a local drugstore. Nitroglycerin ( $0.15 \mathrm{mg}$, Sublingual Tablets) was provided to us by the hospital pharmacy (Hôpital Principal) in Dakar (Senegal). All drugs were serially diluted in distilled water before each experiment. The concentration of the drugs is expressed as final molar concentration in the bath.

\section{Hibuscus sabdariffa extract preparation}

$H$. sabdariffa calyces was obtained from botanical laboratory of our faculty and prepared as previously described (Sarr et al., 2009). In brief, calyces were dried during a week at room temperature. Dried and powdered calyx (Grinder RM-100, Retsch $\AA$ ) of $H$. sabdariffa $(500 \mathrm{~g})$ was extracted by maceration at room temperature for $2 \mathrm{~h}$ with $60 \%$ methanol. The hydroalcoholic extract was then filtered in vacuum conditions (Vacuum pump V-700, Büchi®) by means of the phial of Kitassato and evaporated on a rotary evaporator (Rotavapor R-210, Büchi®). Methanolic extract evaporation was realized during three successive days until the obtaining of a dry crude extract.

\section{Organ chambers experiments}

\section{Vessels preparation}

Experiments were conducted in accordance with the Guide for the Care and Use of Laboratory Animals as promulgated by the Senegalese Academic Bioethics Committee. Male Wistar rats weighing 150 to $200 \mathrm{~g}$ were procured from a local Institute. They were fed on standard rat feed and given free access to water. After anesthesia by intraperitoneal injection of pentothal $(60 \mathrm{mg} / \mathrm{kg}$ body weight) for $10 \mathrm{~min}$, rats were sacrificed and exsanguinated by cross section of the carotid. After supra-umbilical laparotomy, the thoracic aorta was removed carefully from the bottom up, transferred into a petri dish filled with Krebs solution of the following composition (in $\mathrm{mM}):\left(\mathrm{NaCl} 119, \mathrm{KCl} 4.7, \mathrm{KH}_{2} \mathrm{PO}_{4} 1.18, \mathrm{MgSO}_{4} 1.18, \mathrm{CaCl}_{2}\right.$ 1.25, $\mathrm{NaHCO}_{3} 25$ and D-glucose $11, \mathrm{pH} 7.4,37^{\circ} \mathrm{C}$ ) and cleaned of adherent connective tissue. As indicated, the endothelium was removed by rubbing the intimal surface of rings with a pair of forceps and cut into $3 \mathrm{~mm}$ ring segments.

\section{Protocol design}

Dose response studies are typically conducted to assess concentration-response relationships in isolated rat thoracic aorta preparation which allow maintaining the integrity of the tissue for several hours in a temperature-controlled environment, while physiological measurements are performed. The rings were suspended between two wire hooks in organ chambers filled with $10 \mathrm{ml}$ of $\mathrm{Krebs}$ solution $\left(37^{\circ} \mathrm{C}\right.$, pH 7.40$)$ aerated with $\mathrm{O}_{2} 95 \% / \mathrm{CO}_{2}$ $5 \%$. The upper hook was connected to a force transducer (PanlabTRI 202P), and changes in isometric force were recorded (Labscribe® Iworx/118 Data Recording Sofware). After a resting tension $(1 \mathrm{~g})$ defined by preliminary studies, the rings were allowed to equilibrate for $45 \mathrm{~min}$ and were then precontracted with $60 \mathrm{mM}$ potassium chloride to determine maximal contraction. The rings were washed twice with a fresh buffer solution and then precontracted with norepinephrine $\left(10^{-6} \mathrm{M}\right)$ to reach an optimal constriction ( $80 \%$ maximum). Pre-contracted rings were allowed to plateau and then acetylcholine $\left(10^{-6} \mathrm{M}\right)$ was added to assess the endothelial function. Only rings that exhibited less than $10 \%$ relaxation responses to acetylcholine were considered without endothelium and used in subsequent experiments. Rat aortic segments were then randomly assigned to one of the 8 groups: 1 Control; 2 - Tolerant (Nitroglycerin (NTG)-treated); 3 - N-acétyl cysteine (NAC) ; 4 - Vitamin C (VIT C) ; 5 - H. sabdariffa extract (HSE), 6 - VIT C-tolerant; 7 - NAC-tolerant and 8 - HSE-tolerant. The concentration of HSE chosen $\left(5.10^{-2} \mathrm{mg} / \mathrm{ml}\right)$ was based on concentration-response data obtained in a previous study (Sarr et al., 2009).

\section{Nitrate tolerance induction}

To induce nitrate tolerance, thoracic aortic segments without 


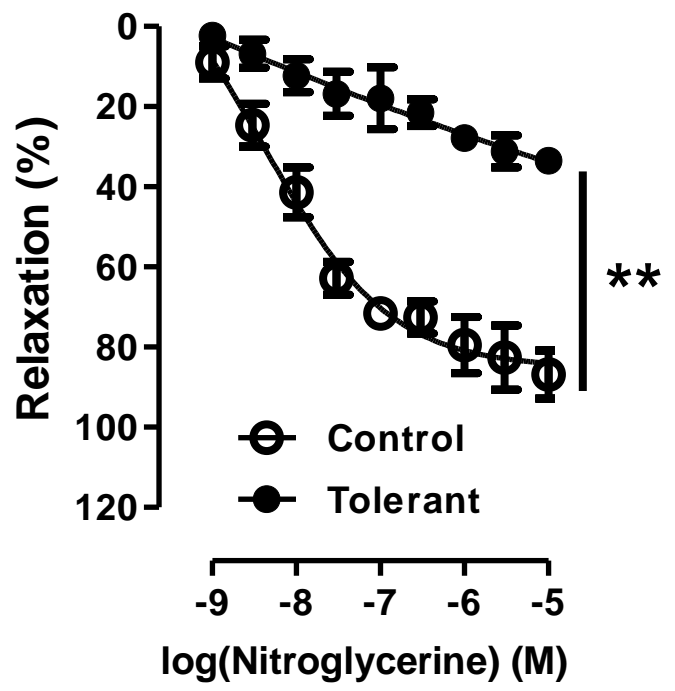

Figure 1. Concentration-effect curves of relaxant response to nitroglycerin in rat thoracic aorta without endothelium (Control) or pre-exposed (Tolerant) to nitroglycerin (NTG, $5.10^{-5} \mathrm{M}, 60 \mathrm{~min}$ ). Results are presented as mean \pm SEM of 7 experiments from 7 rats different. ${ }^{* *}=\mathrm{P}<0.01(2-$ way ANOVA).

Table 1. Relaxing responses of nitroglycerin expressed in percent and $\mathrm{EC}_{50}$ values determined by log-logit regression in rat thoracic aorta without endothelium or tolerant vessels pre-exposed to $H$. sabdariffa extract (HSE), $\mathrm{N}$-acetylcysteine (NAC) or Vitamin C (VIT C).

\begin{tabular}{lcc}
\hline Parameter & $\mathbf{E C}_{50}(\mathbf{M})$ & $\mathbf{E}_{\max }(\%)$ \\
\hline Control & $1.01 \times 10^{-8} \pm 0.05$ & $81.16 \pm 7.42$ \\
Tolerant & $9.69 \times 10^{-8} \pm 0.83$ & $31.33 \pm 4.23$ \\
HSE & $4.68 \times 10^{-9} \pm 0.5$ & $111 \pm 13.91$ \\
NAC & $1.16 \times 10^{-7} \pm 0.03$ & $119 \pm 18.74$ \\
VIT C & $1.62 \times 10^{-8} \pm 0.09$ & $94.19 \pm 11.32$ \\
HSE-tolerant & $4.75 \times 10^{-8} \pm 0.64$ & $66.71 \pm 7.54$ \\
NAC-tolerant & $3.53 \times 10^{-8} \pm 0.08$ & $61.73 \pm 9.26$ \\
VIT C-tolerant & $1.54 \times 10^{-7} \pm 0.12$ & $96.40 \pm 21.13$ \\
\hline
\end{tabular}

endothelium were first exposed to NTG $(50 \mu \mathrm{M}, 1 \mathrm{~h})$ and were precontracted with cumulative concentrations of norepinephrine $\left(10^{-8}\right.$ to $\left.10^{-5} \mathrm{M}\right)$. When a plateau phase was obtained, cumulative concentration-response curves were obtained with NTG concentrations ranging from $10^{-9}$ to $10^{-5} \mathrm{M}$.

\section{Prevention of nitroglycerin-induced nitrate tolerance}

Before induction of tolerance state, the aortic segments were preexposed to one of the antioxidants taken as reference. To do this, they were treated with NAC $\left(10^{-3} \mathrm{M}\right)$, VIT $\mathrm{C}\left(10^{-2} \mathrm{M}\right)$ or HSE $(0.1$ $\mathrm{mg} / \mathrm{ml})$. After $30 \mathrm{~min}$ exposition, they were pre-contracted with norepinephrine $\left(10^{-8}\right.$ to $\left.10^{-5} \mathrm{M}\right)$. When a plateau phase was reached, cumulative concentration-response curves were obtained with NTG concentrations ranging from $10^{-9}$ to $10^{-5} \mathrm{M}$.

\section{Statistical analysis}

Values are expressed as mean \pm standard error of mean (SEM). Concentration-response curves were compared by 2-way Analysis of Variance (ANOVA) or the multi-analysis of variance (MANOVA), as required. Values of $p<0.05$ were considered statistically significant.

\section{RESULTS}

\section{Nitrate tolerance induction}

Results obtained in our study (Figure 1) clearly indicate a tolerance state in NTG-treated vessels. Indeed, after exposure of aorta rings with NTG, there was a significant reduction of at least $40 \%$ of the maximum relaxation to nitroglycerin (tolerant vessels: half maximal effective concentration $\left(\mathrm{EC}_{50}\right)=9.695 \times 10^{-8} \pm 0.831 \mathrm{M} ; \mathrm{E}_{\max }=$ $31.33 \pm 4.23 \%$ ) compared to control (non-tolerant vessels: $\mathrm{EC}_{50}=1.015 \times 10^{-8} \pm 0.054 \mathrm{M} ; \mathrm{E}_{\max }=81.16 \% \pm$ 7.42) as indicated in Table 1 . This loss of the ability of relaxation observed in tolerant vessels highlights, in our model, the phenomenon of treatment failure associated with prolonged use of nitrates.

\section{Potentiating effects of $\boldsymbol{H}$. sabdariffa extract on the relaxant responses to nitroglycerin}

In order to examine any potentiating effect on the NTGinduced relaxations $\left(10^{-9}\right.$ to $\left.10^{-5} \mathrm{M}\right)$ after HSE preexposure at a final concentration of $5.10^{-2} \mathrm{mg} / \mathrm{ml}$ during 30 min, we compare relaxations in HSE-exposed vessels with those obtained with control (not pre-exposed). Results obtained in Figure 2A showed in HSE-exposed vessels, a potentiating of the relaxant response to NTG $\left(\mathrm{EC}_{50}=4.679 \times 10^{-9} \pm 0.498 \mathrm{M} ; \mathrm{E}_{\max }=111 \% \pm 13.91\right)$ compared to control vessels, for which the maximal effect is only about $81.16 \% \pm 7.42\left(\mathrm{EC}_{50}=1.015 \times 10^{-8} \pm 0.054\right.$ M). This demonstrates the ability of the $H$. sabdariffa polyphenolic extract to potentiate the pharmacological vasorelaxant effects of nitrates (Table 1).

In parallel, we studied the effects of two known antioxidants, namely NAC and VIT C on the relaxant responses to NTG in order to verify whether the potentiating effects of HSE can be due to its antioxidant character. For this, we also compare relaxations obtained after NAC or VIT C pre-exposure with those obtained with control not exposed. Our results as indicated in Figure 2B actually showed a potentiating effect of NAC only at high concentrations (10 ${ }^{-5} \mathrm{M} \mathrm{NTG)}$ compared to the control vessels $\left(\mathrm{EC}_{50}\right.$ : $1.015 \times 10^{-8} \pm 0.054 \mathrm{M}$ versus $1.163 \times 10^{-7}$ 

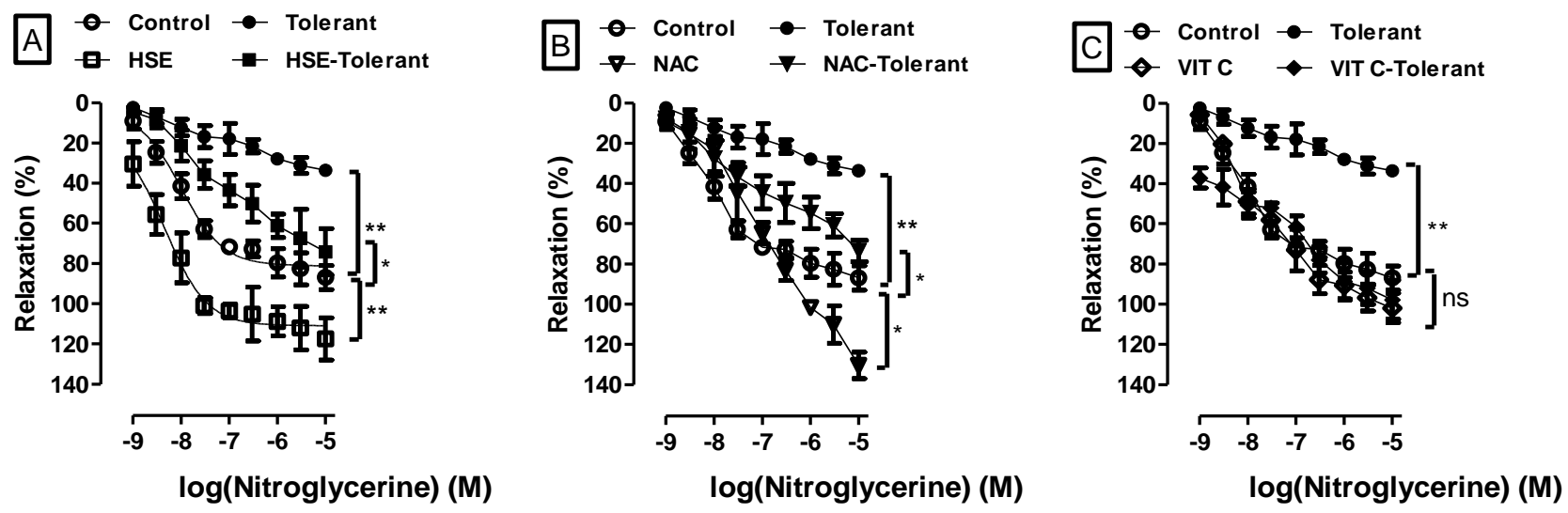

Figure 2. Concentration-effect curves of relaxant responses to nitroglycerin in rat thoracic aorta without endothelium (Control) or tolerant vessels (NTG, $5.10^{-5} \mathrm{M}, 60 \mathrm{~min}$ ), pre-exposed to (A) H. sabdariffa extract (HSE, $\left.5.10^{-2} \mathrm{mg} / \mathrm{ml}\right),(\mathrm{B})$ $\mathrm{N}$-acetylcysteine (NAC, $10^{-3} \mathrm{M}$ ) and (C) Vitamin C (VIT C, $10^{-2} \mathrm{M}$ ) during $30 \mathrm{~min}$.

Results are presented as mean \pm SEM of 7 experiments from 7 different rats. ns $=$ not significant, ${ }^{*}=p<0.05,{ }^{* *}=p<$ 0.01 (MANOVA) compared to control.

\pm 0.029 and $E_{\max }: 81.16 \% \pm 7.42$ versus $119 \% \pm 18.74$ Control versus NAC, respectively). For Vit C, as indicated on Figure $2 \mathrm{C}$, no significant improvements in relaxation responses were observed $\left(\mathrm{EC}_{50}: 1.015 \pm 0.054 \times 10^{-8} \mathrm{M}\right.$ versus $1.620 \pm 0.091 \times 10^{-8}$ and $E_{\max }: 81.16 \% \pm 7.42$ versus $94.19 \% \pm 11.32$; Control versus VIT C, respectively). Thus, compared to NAC, the HSE better potentiates the vasorelaxant response to NTG, since this potentiating was observed for all doses in the range of relaxation. These results indicate a potential benefit role of HSE, while more potentiating the relaxant responses of NTG compared to other antioxidants NAC and VIT C.

\section{Normalizing effects of $\boldsymbol{H}$. Sabdariffa extract in tolerance conditions}

Since some antioxidants potentiate the relaxant responses of NTG, we first sought to determine whether the responses in antioxidant-tolerant aortic segments were different to those obtained in control vessels (without any treatment). If it is the case, we can conclude a normalizing effect by the antioxidant. The results, as shown in Figure $2 \mathrm{~A}$, show a significant difference between the HSE-tolerant $\left(\mathrm{EC}_{50}=4.75 \times 10^{-8} \pm 0.64 ; \mathrm{E}_{\max }=\right.$ $66.71 \% \pm 7.54)$ and control vessels $\left(E_{50}: 1.015 \times 10^{-8} \pm\right.$ $0.054 \mathrm{M}$; $\mathrm{E}_{\max }: 81.16 \% \pm 7.42$ ) demonstrating the non possibility of HSE to normalize the relaxant responses to NTG in tolerant vessels. Also, in comparison to the same untreated control, NAC-treated tolerant vessels did not normalize the relaxing effects of cumulatively administered NTG (Figure 2B), since a significant difference was observed between NAC-tolerant $\left(\mathrm{EC}_{50}=3.53 \times 10^{-8}\right.$ $\left.\pm 0.08 \mathrm{M} ; \quad E_{\max }=61.73 \% \pm 9.26\right)$ and control vessels
$\left(E_{50}: 1.015 \times 10^{-8} \pm 0.054 \mathrm{M} ; E_{\max }: 81.16 \% \pm 7.42\right)$.

However, this result contrasts with those obtained with VIT C, under the same conditions. Indeed, VIT C, without having potentiating effects on NTG-induced relaxation, normalized relaxation responses. Indeed, the results in Figure 2C showed no significant difference between VIT C-tolerant vessels $\left(\mathrm{EC}_{50}=1.62 \pm 0.09 .10^{-8} \mathrm{M} ; \mathrm{E}_{\max }=\right.$ $94.19 \% \pm 11.32)$ and non-tolerant controls $\left(E_{50}: 1.015 \pm\right.$ $0.054 \times 10^{-8} \mathrm{M}$; $\left.\mathrm{E}_{\max }: 81.16 \% \pm 7.42\right)$. It is interesting to note that VIT $C$ has only potentiating effect in tolerant vessels.

\section{Preventive role of $H$. Sabdariffa extract on the tolerance induction}

In order to investigate the ability of HSE to prevent the development of tolerance, we first incubated aortic segments with the HSE before inducing the tolerance phenomenon. A preventive effect on tolerance induction was obtained when any significant difference was observed between relaxant responses in HSE-treated vessels with those of HSE-tolerant vessels. Figure $2 \mathrm{~A}$ showed a significant difference in the relaxant responses between HSE $\left(\mathrm{EC}_{50}=4.68 \times 10^{-9} \pm 0.5 \mathrm{M} ; \mathrm{E}_{\max }=111 \% \pm\right.$ 13.91) and HSE-tolerant vessels $\left(E_{50}=4.75 \times 10^{-8} \pm\right.$ $0.64 ; E_{\max }=66.71 \% \pm 7.54$ ), showing a continuing state of tolerance. Thus, we conclude that HSE is not able to prevent nitrates tolerance, as well as NAC (Figure 2B). By contrast, VIT C completely reverse tolerance to nitroglycerin and any significant different were found between VIT-treated and VIT-tolerant vessels as shown in Figure 2C. 


\section{DISCUSSION}

The aim of the present study was to evaluate the ability of a Senegalese and African Pharmacopoeia plant extract to prevent the development of nitrates tolerance. In light of all of our results, the polyphenol-rich extract of $H$. sabdariffa are able to potentiate the relaxant responses to nitroglycerin in non-tolerant and tolerant denudedthoracic aortic rings; partially correcting the nitrate tolerance by normalizing the relaxant responses to nitroglycerin but can not prevent the development of this phenomenon.

Regarding the methodological approach, we used an in vitro nitrates tolerance induction model, which was already validated in numerous studies (Wang et al., 2002a; Van de Voorde et al., 1987, 1994; Stewart et al., 1989; Ratz et al., 2000; Otto et al., 2005; Chegaev et al., 2009; Bennett et al., 1988; Sarr et al., 2005). To do this, we used aortic denuded-rings in order to avoid possible interference between the exogenous nitrogen oxide (NO) from nitroglycerin and endothelium-derived one. The model is established when we observe a significant reduction in the relaxant response to nitroglycerin. This simple model allows overcoming the influence of neurohumoral counter-regulatory involved in vascular physiology.

Among factors involved in reducing the bioavailability of $\mathrm{NO}$, recent work reported by researchers confirm that the development of tolerance to nitrates is associated with increased oxidative stress (Oelze et al., 2010; Daiber et al., 2009a; DiFabio et al., 2006; Muller et al., 2004; Parker, 2004; Gori et al., 2001; Laight et al., 1997, 1998). In addition, a key enzyme involvement of nitroglycerin and nitrates biotransformation, namely the mitochondrial aldehyde dehydrogenase (ALDH 2), is inhibited by reactive oxygen species (ROS) which in addition, can degrade nitric oxide (Wenzel et al., 2009a, 2009b; Daiber et al., 2004, 2009b; Sydow et al., 2004). Therefore, it would be interesting to study the benefit of antioxidants in preventing nitrate tolerance development.

Regarding the natural antioxidants, various therapeutic interventions have been considered and evaluated experimentally or clinically in order to improve endothelial function, the evolution of certain diseases affecting the vascular system and the prevention of tolerance to nitrates. These natural antioxidants include vitamin C, vitamin $\mathrm{E}$ and flavonoids. Moreover, the results of many clinical studies, particularly the Heart Outcomes Prevention Evaluation (HOPE) study (Yusuf et al., 2000) showed that vitamin $E$ had no beneficial effect in patients with high cardiovascular risk. The Italian Group for the Study of Streptokinase nell'Infarto (GISSI) study (Hopper et al., 1999) meanwhile showed that in contrast to polyunsaturated fatty acids $n-3$ (or omega 3 ), vitamin $E$ does not decrease significantly the incidence of cardiovascular events among patients who have survived a myocardial infarction. These studies have also reported the limited effectiveness of these antioxidant vitamins, especially their low bioavailability following oral administration or some compartmentalization problems, and their ability to produce free radicals after reacting with oxidizing molecules. Thus it has been reported that vitamin $E$ is capable of producing a tocopheroxyl radical and in the case of vitamin C, ascorbyl radical can be generated (Carr and Frei, 2000), to the extent that until now the results obtained with different classes of antioxidants, including vitamins, are not really satisfactory and further studies with other compounds remains justified.

Indeed, it is now accepted that polyphenols could prevent many diseases such as cancers (Yang et al., 2009; Korkina et al., 2009; Khan et al., 2009; Bracke et al., 2008; Franklin and McCubrey, 2007), cardiovascular (Madeira et al., 2009; Jones et al., 2011; Kumar et al., 2008; Agouni et al., 2009; Walter et al., 2008; SchiniKerth et al., 2011; Sall Diallo et al., 2008; Sarr et al., 2006 ; 2009) and degenerative diseases (Mollnau et al., 2006; Chen et al., 2007; Berrino, 2002; Meydani, 2002; Meydani, 2001). Encouraging the consumption of fruits and vegetables is now a major public health recommendation. Moreover, among the plant antioxidants, polyphenols appear to be the most effective in their protective effects. The polyphenols in $\mathrm{H}$. sabdariffa were identified by a study conducted in our laboratory (Sarr et al., 2009) and many classes were found: phenolic, chlorogenic and caffeic acids, anthocyanins and flavonoids. This same study also found that polyphenols have a good vasorelaxant activity in vitro. What about their efficacy on tolerance to nitrates? The main results obtained during the present study have clearly demonstrated the interest of polyphenols on nitrate tolerance.

One important result obtained in our study is the potentiation of the relaxant responses to nitroglycerin with the $H$. sabdariffa extract, whatever the type of vessels, tolerant or not tolerant. Similarly, potentiating effects were also found with $\mathrm{N}$-acetyl cysteine. If potentiating response of nitroglycerin by antioxidants such as $\mathrm{N}$-acetyl cysteine have been reported in numerous studies (Munzel et al., 1989; Pizzulli et al., 1997; Watanabe et al., 1998a, 1998b), few data relate those of plant polyphenols, and no data was reported for the polyphenols of $H$. sabdariffa. To our knowledge, such results linking these potentiating effects on relaxation responses to nitroglycerin and polyphenols from $H$. sabdariffa is an original result.

Another important result is that these potentiating responses of the $H$. sabdariffa extract on the responses of nitroglycerin are responsible for the continuing state of tolerance. This result is explained by the fact that the HSE potentiate all types of vessels relaxed with nitroglycerin, which persist the state of tolerance. This result is very interesting because it can be a possibility to 
significantly reduce the therapeutic doses of nitroglycerin and delay the development of tolerance. Similar results were also found with NAC but not with VIT C. These results are consistent with those reported by Pizzuli et al. (1997), showing that NAC does not prevent tolerance during nitroglycerin infusion in patients with heart failure. However, the concomitant infusion of NAC and NTG in $48 \mathrm{~h}$ continuous infusion attenuates the development of nitrate tolerance in patients with normal left ventricular function. Regarding vitamin C, Watanabe et al. (1998b) have also shown that oral administration of this antioxidant may prevent nitrate tolerance during continuous administration of NTG in patients with ischemic heart disease.

Finally, data obtained with apocynin, a polyphenols structural analogue, reported by Fukatsu et al. (2007) indicated that this compound, pharmacologically known to be able to prevent the increase in protein expression of NADPH oxidase, a source of superoxide anions, could be a means of protection against nitrate tolerance.

\section{Conclusion}

In the long-term treatment of angina pectoris, the difficulty observed is the gradual reduction of coronary arteries relaxant responses to nitrates, despite increasing doses. Our work performed to assess the potential of $H$. sabdariffa polyphenols suggests interesting therapeutic prospects. This could improve the coronary relaxation responses by potentiating the relaxing effect of nitroglycerin.

\section{REFERENCES}

Agouni A, Lagrue-Lak-Hal AH, Mostefai HA, Tesse A, Mulder P, Rouet $P$, Desmoulin F, Heymes C, Martinez MC, Andriantsitohaina R (2009). Red wine polyphenols prevent metabolic and cardiovascular alterations associated with obesity in Zucker fatty rats (Fa/Fa). PLoS One 4(5): e5557.

Bennett BM, Schroder H, Hayward LD, Waldman SA,Murad F (1988). Effect of in vitro organic nitrate tolerance on relaxation, cyclic GMP accumulation, and guanylate cyclase activation by glyceryl trinitrate and the enantiomers of isoidide dinitrate. Circ. Res. 63(4):693-701.

Bracke ME, Vanhoecke BW, Derycke L, Bolca S, Possemiers S, Heyerick A, Stevens CV, De Keukeleire D, Depypere HT, Verstraete W, Williams CA, McKenna ST, Tomar S, Sharma D, Prasad AK, DePass AL, armar VS (2008). Plant polyphenolics as anti-invasive cancer agents. Anticancer Agents Med. Chem. 8(2):171-185.

Cai H, Harrison DG (2000). Endothelial dysfunction in cardiovascular diseases: the role of oxidant stress. Circ. Res. 87(10):840-844.

Carevic V, Rumboldt M, Rumboldt Z (2007). Coronary heart disease risk factors in Croatia and worldwide: results of the Interheart study. Acta Med. Croatica 61(3): 299-306.

Carr A, Frei B (2000). The role of natural antioxidants in preserving the biological activity of endothelium-derived nitric oxide. Free Radic Biol. Med. 28(12):1806-1814.

Chegaev K, Lazzarato L, Marcarino P, Di Stilo A, Fruttero R, Vanthuyne N, Roussel C, Gasco A (2009). Synthesis of some novel organic nitrates and comparative in vitro study of their vasodilator profile. J.
Med. Chem. 52(13):4020-4025.

Chen LW, Wang YQ, Wei LC, Shi M, Chan YS (2007). Chinese herbs and herbal extracts for neuroprotection of dopaminergic neurons and potential therapeutic treatment of Parkinson's disease. CNS Neurol Disord Drug Targets 6(4):273-281.

Daiber A, Gori T, Munzel T (2010a). Mechanisms and clinical significance of nitrate tolerance. Pharm Unserer Zeit 39(5):375-384.

Daiber A, Mulsch A, Hink U, Mollnau H, Warnholtz A, Oelze M, Munzel $T$ (2005). The oxidative stress concept of nitrate tolerance and the antioxidant properties of hydralazine. Am. J. Cardiol. 96(7B):25i-36i.

Daiber A, Munzel T, Gori T (2010b). Organic nitrates and nitrate tolerance--state of the art and future developments. Adv. Pharmacol. 60:177-227.

Daiber A, Oelze M, Coldewey M, Bachschmid M, Wenzel P, Sydow K, Wendt M, Kleschyov AL, Stalleicken D, Ullrich V, Mulsch A, Munzel T (2004). Oxidative stress and mitochondrial aldehyde dehydrogenase activity: a comparison of pentaerythritol tetranitrate with other organic nitrates. Mol. Pharmacol. 66(6):1372-1382.

Daiber A, Oelze M, Wenzel P, Wickramanayake JM, Schuhmacher S, Jansen T, Lackner KJ, Torzewski M, Munzel T (2009a). Nitrate tolerance as a model of vascular dysfunction: roles for mitochondrial aldehyde dehydrogenase and mitochondrial oxidative stress. Pharmacol. Rep. 61(1):33-48.

Daiber A, Wenzel P, Oelze M, Schuhmacher S, Jansen T, Munzel T (2009b). Mitochondrial aldehyde dehydrogenase (ALDH-2)--maker of and marker for nitrate tolerance in response to nitroglycerin treatment. Chem. Biol. Interact. 178(1-3):40-47.

DiFabio JM, Thomas GR, Zucco L, Kuliszewski MA, Bennett BM, Kutryk MJ, Parker JD (2006). Nitroglycerin attenuates human endothelial progenitor cell differentiation, function, and survival. J. Pharmacol. Exp. Ther. 318(1):117-123.

Fadel PJ, Farias I, Gallagher M, Wang KM, Thomas Z (2012) Oxidative stress and enhanced sympathetic vasoconstriction in contracting muscles of nitrate-tolerant rats and humans. J. Physiol. 590(Pt 2): 395-407.

Fink B, Bassenge E (2002). Association between vascular tolerance and platelet upregulation: comparison of nonintermittent administration of pentaerithrityltetranitrate and glyceryltrinitrate. J. Cardiovasc. Pharmacol. 40(6):890-897.

Franklin RA, McCubrey JA (2007). Polyphenols in breast cancer treatment. Cancer Biol. Ther. 6(1):62-63.

Fukatsu A, Hayashi T, Miyazaki-Akita A, Matsui-Hirai H, Furutate Y, Ishitsuka A, Hattori Y, Iguchi A (2007). Possible usefulness of apocynin, an NADPH oxidase inhibitor, for nitrate tolerance: prevention of NO donor-induced endothelial cell abnormalities. Am. J. Physiol. Heart Circ. Physiol. 293(1):H790-797.

Gori T, Burstein JM, Ahmed S, Miner SE, Al-Hesayen A, Kelly S, Parker JD (2001). Folic acid prevents nitroglycerin-induced nitric oxide synthase dysfunction and nitrate tolerance: a human in vivo study. Circ. 104(10):1119-1123.

Hopper L, Ness A, Higgins JP, Moore T, Ebrahim S (1999). GISSIPrevenzione trial. Lancet 354(9189):1557.

Jones AM, Grassi B, Christensen PM, Krustrup P, Bangsbo J, Poole DC (2011). Slow component of VO2 kinetics: mechanistic bases and practical applications. Med. Sci. Sports Exerc. 43(11):2046-2062.

Kagan VE, Yalowich JC, Day BW, Goldman R, Gantchev TG, Stoyanovsky DA (1994). Ascorbate is the primary reductant of the phenoxyl radical of etoposide in the presence of thiols both in cell homogenates and in model systems. Biochem. 33(32):9651-9660.

Khan N, Adhami VM, Mukhtar H (2009). Review: green tea polyphenols in chemoprevention of prostate cancer: preclinical and clinical studies. Nutr. Cancer 61(6): 836-841.

Korkina LG, De Luca C, Kostyuk VA, Pastore S (2009). Plant polyphenols and tumors: from mechanisms to therapies, prevention, and protection against toxicity of anti-cancer treatments. Curr. Med. Chem. 16(30): 3943-3965.

Kumar A, Mishra P, Ghosh S, Sharma P, Ali M, Pandey BN, Mishra KP (2008). Thorium-induced oxidative stress mediated toxicity in mice and its abrogation by diethylenetriamine pentaacetate. Int. J. Radiat. 
Biol. 84(4): 337-349.

Laight DW, Carrier MJ, Anggard EE (1997). Investigation of role for oxidant stress in vascular tolerance development to glyceryl trinitrate in vitro. Br. J. Pharmacol. 120(8):1477-1482.

Laight DW, Kengatharan KM, Gopaul NK, Anggard EE, Carrier MJ (1998). Investigation of oxidant stress and vasodepression to glyceryl trinitrate in the obese Zucker rat in vivo. Br. J. Pharmacol. 125(4):895-901.

Madeira SV, Auger C, Anselm E, Chataigneau M, Chataigneau T, Soares de Moura R, Schini-Kerth VB (2009). eNOS activation induced by a polyphenol-rich grape skin extract in porcine coronary arteries. J. Vasc. Res. 46(5):406-416.

Meydani M (2001). Nutrition interventions in aging and age-associated disease. Ann. N. Y. Acad. Sci. 928: 226-235.

Mollnau H, Wenzel P, Oelze M, Treiber N, Pautz A, Schulz E, Schuhmacher S, Reifenberg K, Stalleicken D, Scharffetter-Kochanek K, Kleinert H, Munzel T, Daiber A (2006). Mitochondrial oxidative stress and nitrate tolerance--comparison of nitroglycerin and pentaerithrityl tetranitrate in $\mathrm{Mn}-\mathrm{SOD}+/-$ mice. BMC Cardiovasc. Disord. 6:44.

Muller S, Konig I, Meyer W, Kojda G (2004). Inhibition of vascular oxidative stress in hypercholesterolemia by eccentric isosorbide mononitrate. J. Am. Coll. Cardiol. 44(3): 624-631.

Munzel T (2008). Recent findings on nitrates: their action, bioactivation and development of tolerance. Dtsch. Med. Wochenschr 133(44):2277-2282.

Munzel T, Daiber A, Gori T (2011). Nitrate therapy: new aspects concerning molecular action and tolerance. Circ. 123(19): 2132-2144.

Munzel T, Daiber A, Mulsch A (2005). Explaining the phenomenon of nitrate tolerance. Circ. Res. 97(7): 618-628.

Munzel T, Holtz J, Mulsch A, Stewart DJ, Bassenge E (1989). Failure of the sulfhydryl donor $\mathrm{N}$-acetylcysteine (NAC) to reverse nitrate tolerance in large epicardial arteries and the venous capacitance system of the dog. Z. Kardiol 78 Suppl 2:26-28; discussion 64-7.

Oelze M, Schuhmacher S, Daiber A (2010). Organic nitrates and nitrate resistance in diabetes: the role of vascular dysfunction and oxidative stress with emphasis on antioxidant properties of pentaerithrityl tetranitrate. Exp. Diabetes Res. 2010:213176.

Otto A, Fontaine D, Fontaine J, Berkenboom G (2005). Rosuvastatin treatment protects against nitrate-induced oxidative stress. J. Cardiovasc. Pharmacol. 46(2):177-184.

Parker JD (2004). Nitrate tolerance, oxidative stress, and mitochondrial function: another worrisome chapter on the effects of organic nitrates. J. Clin. Investig. 113(3):352-354.

Pizzulli L, Hagendorff A, Zirbes M, Jung W, Luderitz B (1997). Nacetylcysteine attenuates nitroglycerin tolerance in patients with angina pectoris and normal left ventricular function. Am. J. Cardiol. 79(1):28-33.

Ratz JD, McGuire JJ, Anderson DJ, Bennett BM (2000). Effects of the flavoprotein inhibitor, diphenyleneiodonium sulfate, on ex vivo organic nitrate tolerance in the rat. J. Pharmacol. Exp. Ther. 293(2):569-577.

Sall Diallo A, Sarr M, Mostefai HA, Carusio N, Pricci M, Andriantsitohaina R (2008). Cognac polyphenolic compounds increase bradykinin-induced nitric oxide production in endothelial cells. Physiol. Res. 57(6):885-892.

Sarr M, Chataigneau M, Martins S, Schott C, El Bedoui J, Oak MH, Muller B, Chataigneau T, Schini-Kerth VB (2006). Red wine polyphenols prevent angiotensin II-induced hypertension and endothelial dysfunction in rats: role of NADPH oxidase. Cardiovasc. Res. 71(4):794-802.

Sarr M, Lobysheva I, Diallo AS, Stoclet JC, Schini-Kerth VB, Muller B (2005). Formation of releasable NO stores by S-nitrosoglutathione in arteries exhibiting tolerance to glyceryl-trinitrate. Eur. J. Pharmacol. 513(1-2):119-123.

Sarr M, Ngom S, Kane MO, Wele A, Diop D, Sarr B, Gueye L, Andriantsitohaina R, Diallo AS (2009). In vitro vasorelaxation mechanisms of bioactive compounds extracted from Hibiscus sabdariffa on rat thoracic aorta. Nutr. Metab. 6:45.
Satoh K, Sakagami H, Nakamura K (1996). Enhancement of radical intensity and cytotoxic activity of ascorbate by hyperthermia. Anticancer. Res. 16(5A):2987-2991.

Schini-Kerth VB, Etienne-Selloum N, Chataigneau T, Auger C (2011). Vascular protection by natural product-derived polyphenols: in vitro and in vivo evidence. Planta Med. 77(11):1161-1167.

Stewart DH, Hayward LD, Bennett BM (1989). Differential biotransformation of the enantiomers of isoidide dinitrate in isolated rat aorta. Can. J. Physiol. Pharmacol. 67(11):1403-1408.

Stritzke J, Linsel-Nitschke P, Markus MR, Mayer B, Lieb W, Luchner A, Doring A, Koenig W, Keil U, Hense HW, Schunkert H (2009). Association between degenerative aortic valve disease and long-term exposure to cardiovascular risk factors: results of the longitudinal population-based KORA/MONICA survey. Eur. Heart J. 30(16):20442053.

Sydow K, Daiber A, Oelze M, Chen Z, August M, Wendt M, Ullrich V, Mulsch A, Schulz E, Keaney JF Jr, Stamler JS, Munzel T (2004). Central role of mitochondrial aldehyde dehydrogenase and reactive oxygen species in nitroglycerin tolerance and cross-tolerance. J. Clin. Investig. 113(3):482-489.

Van de Voorde J, Vanheel B, Leusen I (1987). Influence of vascular tolerance to nitroglycerin on endothelium-dependent relaxation. Arch. Int. Pharmacodyn. Ther. 290(2):215-221.

Van de Voorde J, Vyt S, Vanheel B (1994). The basal endothelial inhibitory influence on vascular tone is not affected in nitroglycerintolerant rat aorta. Can. J. Physiol. Pharmacol. 72(9):1094-1097.

Walter A, Etienne-Selloum N, Sarr M, Kane MO, Beretz A, Schini-Kerth VB (2008). Angiotensin II induces the vascular expression of VEGF and MMP-2 in vivo: preventive effect of red wine polyphenols. J. Vasc. Res. 45(5):386-394.

Wang EQ, Lee WI, Brazeau D, Fung HL (2002a). cDNA microarray analysis of vascular gene expression after nitric oxide donor infusions in rats: implications for nitrate tolerance mechanisms. AAPS Pharm. Sci. 4(2):E10.

Wang EQ, Lee WI, Fung HL (2002b). Lack of critical involvement of endothelial nitric oxide synthase in vascular nitrate tolerance in mice. Br. J. Pharmacol. 135(2):299-302.

Watanabe H, Kakihana M, Ohtsuka S, Sugishita Y (1998a). Randomized, double-blind, placebo-controlled study of ascorbate on the preventive effect of nitrate tolerance in patients with congestive heart failure. Circ. 97(9):886-891.

Watanabe H, Kakihana M, Ohtsuka S, Sugishita Y (1998b). Randomized, double-blind, placebo-controlled study of the preventive effect of supplemental oral vitamin $\mathrm{C}$ on attenuation of development of nitrate tolerance. J. Am. Coll. Cardiol. 31(6):1323-1329.

Wenzel P, Schulz E, Gori T, Ostad MA, Mathner F, Schildknecht S, Gobel S, Oelze M, Stalleicken D, Warnholtz A, Munzel T, Daiber A (2009a). Monitoring white blood cell mitochondrial aldehyde dehydrogenase activity: implications for nitrate therapy in humans. J. Pharmacol. Exp. Ther. 330(1):63-71.

Wenzl MV, Wolkart G, Stessel H, Beretta M, Schmidt K, Mayer B (2009b). Different effects of ascorbate deprivation and classical vascular nitrate tolerance on aldehyde dehydrogenase-catalysed bioactivation of nitroglycerin. Br. J. Pharmacol. 156(8):1248--4.

Yusuf S, Dagenais G, Pogue J, Bosch J, Sleight P (2000). Vitamin E supplementation and cardiovascular events in high-risk patients. The Heart Outcomes Prevention Evaluation Study Investigators. N. Engl. J. Med. 342(3):154-160. 